\title{
ПРАВЫЙ ПОПУЛИЗМ: ОСОБЕННОСТИ ПОЛИТИЧЕСКОГО ФЕНОМЕНА
}

Аннотация. В связи с усилением партий политической альтернативы в современной Европе исследования в сфере правого популизма становятся всё более актуальными. $K$ настоящему времени европейская политическая наука выработала общее понимание этого фено́-мена, однако многие теоретические вопросы по-прежнему остаются дискуссионными. В этой статье автор даёт собственное видение популизма как общественнополитического явления и отвечает на вопрос о том, какая партия может быть названа популистской.

Ключевые слова: популизм, партии политической альтернативы, Европейский союз, европейская интеграция, иммиграция, сочииально-экономические проблемы.

В связи с усилением протестных партий популистские технологии в современной европейской политике стали применяться чаще. В то же время следует иметь в виду: какой подробной ни получилась бы общая концепция популизма, каждая партия имеет свои особенности, которые продиктованы не только политической системой и социально-экономическими условиями, но и противниками, против которых выступает та или иная правая популистская партия ${ }^{1}$. Ввиду этого необходимо остановиться на двух принципиально важных моментах: истории фено́мена и общих чертах, присущих всем правопопулистским партиям в Европе.

Термин популизм происходит от латинского слова «роpulus», которое обозначает народ. В политическом лексиконе он впервые стал употребляться в США, где в 1892 г. была основана Популистская партия. Она выступала против господства крупного капитала, за предоставление дешёвых кредитов и введение плебисцитарной демократии. Эта организация нашла поддержку у фермеров на Среднем Западе. Некоторые политологи считают популистами российских «народников», выступавших против форсированного развития капитализма и монархии и видевших процветание русского народа в аграрном социализме ${ }^{2}$. К популистам принято относить авторитарные режимы в 1930-е гг. в Бразилии и Аргентине, которые получали массовую поддержку за счёт привлекательного требования создать протекционистскую экономику и распределять социальные блага в пользу малоимущих и средних слоёв населения ${ }^{3}$. В Западной Европе этот термин вошёл в обиход в 1980-е гг.

Исследование и описание популизма представляется весьма непростой задачей по двум причинам. Первая, по мнению Р. Коллиера, состоит в том, что существующие концепции включают слишком многие составные части, которые трудно привести к общему знаменателю ${ }^{4}$.

(С Грибовский Василий Сергеевич - младший научный сотрудник Отдела социальных и политических исследований, аспирант ИЕ РАН. Aдpec: 125009, Россия. Москва, ул. Моховая, д. 11, стр. 3. E-mail: vasily.gribovsky.92@mail.ru.

DOI: http://dx.doi.org/10.15211/vestnikieran120196164

${ }^{1}$ Goetz N. Bedeutung und Tendenzen des Rechtspopulismus unter Berücksichtigung des Aspekts Migration, München, 2006. S. 3.

${ }^{2}$ Werner T. Bauer. Rechtsextreme und rechtspopulistische Parteien in Europa. Wien, 2014. S. 5.

${ }^{3}$ Werz N. Populismus. Populisten in Übersee und Europa, Opladen 2003. S. 15-43.

${ }^{4}$ Collier R. Populism. International Encyclopedia of Social and Behavioral Sciences, Oxford: Elsevier. 2001. P. 5. 
Такого же мнения придерживается Ренсманн, признавая популизм весьма условной научной категорией ввиду его многослойности и зачастую расплывчатости ${ }^{1}$. Вторая же кроется в том, что термин используется преимущественно в негативном ключе не только в публичной, но и в академической средах и исследуется в целом как своего рода общественная-политическая патология ${ }^{2}$. Так, например, О. Геден писал об отсутствии «действенного рецепта против правого популизма в Европе» ${ }^{3}$. У. Альтерматт даже использует медицинский термин «правопопулистский синдром» ${ }^{4}$. Иными словами, результаты исследования во многом закладываются ещё до его начала.

По мере изучения популизма в европейской политической науке сформировался основной подход к проблеме. Так, М. Канован утверждает, что правый популизм - это политический стиль, нацеленный на завоевание максимально широкой общественной поддержки 5 . Ф. Декер считает, что популизм - это спекуляция страхами населения в собственных узкопартийных целях посредством простых и ясных решений политических проблем ${ }^{6}$. К. Мудде полагает, что популизм обозначает политический стиль, связанный с крайним упрощением политики и относящийся не столько к содержанию, сколько к стилю7. А. Цинелль подчёркивает, что деятельность популистских партий всегда направлена против сложившейся политической системы ${ }^{8}$. По мнению Н. Гётц, популизм - это скачкообразная политика, которая не содержит никаких фундаментальных политических идей и нацелена на получение немедленной поддержки избирателей 9 .

Политологи пришли к выводу, что в основе популизма лежит противопоставление социальных и национальных групп в рамках одного общества ${ }^{10}$. Во-первых, популисты разделяют общество на две большие и противопоставленные друг другу группы, т.е. «непорочный народ» и «коррупированные элиты» ${ }^{11}$. Постоянная отсылка «к народу» является лейтмотивом политики популистов в целом и правых популистов, в частности. Народ понимается как «молчащее большинство», чьими единственными защитниками позиционируют себя правые популисты $^{12}$. Отсюда проистекает тезис о том, что политика должна быть выражением некоей общей воли народа ${ }^{13}$. По этой причине они остро критикуют нынешнюю политическую систему и требуют радикально преобразовать её ${ }^{14}$. Характерно и то, что, пытаясь отличиться от власти, популисты зачастую называют свои организации «движениями», «избирательными

\footnotetext{
${ }^{1}$ Pelinka A. Die FPÖ in der vergleichenden Parteienforschung. Österreichische Zeitschrift für Politikwissenschaft №31, 2002. S. 285.

${ }_{3}^{2}$ Mudde C. Voices of the People: Populism in Europe and Latin America Compared. Working Paper №378, 2011. P. 4.

${ }^{3}$ Geden O. Rechtspopulismus. Funktionslogiken - Gelegenheitsstrukturen - Gegenstrategien. Berlin: Stiftung Wissenschaft und Politik, 2007. S. 5.

${ }_{5}^{4}$ Altermatt U. Das Fanal von Sarajevo. Ethnonationalismus in Europa, Paderborn, 1996. S. 193.

${ }_{6}^{5}$ Canovan M. Populism, New York: Harcourt, 1981. P. 261.

${ }_{7}^{6}$ Decker F. Populismus. Gefahr für die Demokratie oder nützliches Korrektiv? Wiesbaden., 2006. S. 1.

${ }^{7}$ Mudde C. The Populist Zeitgeist. Government and Opposition 39 (4), 2004. P. 541-563.

${ }^{8}$ Zinnel A. Moderner Rechtspopulismus in Frankreich, Frankfurt am Main, 1996. S. 15-18.

${ }^{9}$ Goetz N. Bedeutung und Tendenzen des Rechtspopulismus unter Berücksichtigung des Aspekts Migration, München, 2006. S. 4.

${ }_{10}^{10}$ Pelinka A. Die FPÖ in der vergleichenden Parteienforschung. Zur typologischen Einordnung der Freiheitlichen Partei Österreichs. Österreichische Zeitschrift für Politikwissenschaft, №3, 2002, S. 281-290.

${ }^{11}$ Decker F. Parteien unter Druck. Der neue Rechtspopulismus in den westlichen Demokratien. Opladen: Leske und Budrich Verlag, 2000. S. 50.

${ }^{12}$ Geden O. Rechtspopulismus. Funktionslogiken - Gelegenheitsstrukturen - Gegenstrategien. Berlin: Stiftung Wissenschaft und Politik, 2007. S. 9.

${ }_{13}^{13}$ Mudde C. The Populist Zeitgeist. Government and Opposition №4, 2002. S. 41-63.

${ }_{14}$ Decker F. Parteien unter Druck. Der neue Rechtspopulismus in den westlichen Demokratien. Opladen: Leske und Budrich Verlag, 2000. S. 50.
}

Научно-аналитический вестник ИЕ РАН, 2019, №1 
платформами», «лигами», «союзами», «фронтами» и т.д. ${ }^{1}$

Во-вторых, симптоматично, что «народом» правые популисты считают только коренное население. Это говорит о восприятии ими народа как гомогенной единицы ${ }^{2}$. По этой причине не они особенно рьяно педалируют вопросы национального самосознания и культурной иден-тичности ${ }^{3}$. В этой связи, как констатирует А. Пелинка, к образу вертикального врага (противостояние народа и элит) добавляется образ врага горизонтального ${ }^{4}$. Они рассматривают иммигрантов исключительно как угрозу общему и частному социальноэкономическому благо-получию 5 и культурной идентичности 6 . Власть же, по мнению правых вых популистов, скрыто поддерживает враждебную деятельность «чужих» или недостаточно последовательно препят-ствует ей ${ }^{7}$.

Исходя из вышеизложенных соображений, можно сделать вывод о том, что популизм правильнее рассматривать как политический стиль, нежели в качестве идеологии. Во-первых, идеология представляет собой продуманную систему взглядов, которую та или иная политическая сила проецирует на решение общественно значимых проблем. В то же время популизм как таковой не содержит в себе какой-либо определённой программы. Ведь популистами могут быть и правые и левые партии, чьи политические взгляды разительно различаются и не могут быть сведены к общей идеологии. Во-вторых, ошибка многих европейских исследователей состоит в том, что они исследуют евроскептицизм и популизм в отрыве друг от друга. По нашему мнению, речь идёт о двух сторонах одного и того же явления - партийного протеста, где одна сторона (евроскептицизм) представляет собой программу действий, а другая (популизм) - манеру его общественно-политической подачи.

Изучение имеющихся теоретических разработок в области правого популизма приводит нас к выводу о том, что он представляет собой особый политический стиль поведения партии, направленный на завоевание симпатий протестного и пассивного электората посредством предложения простых решений сложнейших проблем и противопоставления одних национальных и социальных групп населения другим.

Соответственно, популистская партия - это политическая партия, ориентирующаяся преимущественно на протестные и электорально пассивные группы населения, не имеющая проработанной предвыборной программы и предлагающая моментальные решения актуальных вопросов социально-экономической и культурной жизни общества.

\section{Список литературы}

Altermatt U. Das Fanal von Sarajevo. Ethnonationalismus in Europa, Paderborn, 1996. S. 193.

Betz H.-G., Rechtspopulismus und Ethnonationalismus. Erfolgsbedingungen und Zukunftschancen. Politik im 21 Jahrhundert, №5 2006. S. 126.

Binder T. Die Wahlerfolge rechtspopulistischer Parteien - eine Folge von Modernisierungsprozessen? Berlin, 2005. S. 4.

\footnotetext{
${ }^{1}$ Betz H.-G., Rechtspopulismus und Ethnonationalismus. Erfolgsbedingungen und Zukunftschancen. Politik im 21 Jahrhundert, №5 2006. S. 126.

2 Pfahl-Traughber A. Volkes Stimme? Rechtspopulismus in Europa, Bonn, 1994. S. 136.

${ }^{3}$ Binder T. Die Wahlerfolge rechtspopulistischer Parteien - eine Folge von Modernisierungsprozessen? Berlin, 2005 . S. 4.

${ }^{4}$ Pelinka F. Die FPÖ in der vergleichenden Parteienforschung. Zur typologischen Einordnung der Freiheitlichen Partei

Österreichs. Rechtspopulismus und Rechtsradikalismus in Europa. №3 2002. S. 281-290.

${ }^{5}$ Binder T. Op. cit. S. 6.

${ }^{6}$ Grabow K., Hartleb F. Europa - Nein Danke? Berlin: Konrad-Adenauer-Stiftung, 2013. S. 11.

${ }^{7}$ Geden O. Rechtspopulismus. Funktionslogiken - Gelegenheitsstrukturen - Gegenstrategien. Berlin: Stiftung Wissenschaft und Politik, 2007. S. 10.
}

Научно-аналитический вестник ИЕ РАН, 2019, №1 
Canovan M. Populism, New York: Harcourt, 1981. P. 261.

Collier R. Populism. International Encyclopedia of Social and Behavioral Sciences, Oxford: Elsevier. 2001. P. 5.

Decker F. Parteien unter Druck. Der neue Rechtspopulismus in den westlichen Demokratien. Opladen: Leske und Budrich Verlag, 2000. S. 50.

Decker F. Populismus. Gefahr für die Demokratie oder nützliches Korrektiv? Wiesbaden., 2006. S. 1.

Geden O. Rechtspopulismus. Funktionslogiken - Gelegenheitsstrukturen - Gegenstrategien. Berlin: Stiftung Wissenschaft und Politik, 2007. S. 5.

Goetz N. Bedeutung und Tendenzen des Rechtspopulismus unter Berücksichtigung des Aspekts Migration, München, 2006. S. 3.

Grabow K., Hartleb F. Europa - Nein Danke? Berlin: Konrad-Adenauer-Stiftung, 2013. S. 11.

Mudde C. The Populist Zeitgeist. Government and Opposition 39 (4), 2004. P. 541-563.

Mudde C. Voices of the People: Populism in Europe and Latin America Compared. Working Paper №378, 2011. P. 4.

Pfahl-Traughber A. Volkes Stimme? Rechtspopulismus in Europa, Bonn, 1994. S. 136.

Pelinka A. Die FPÖ in der vergleichenden Parteienforschung. Österreichische Zeitschrift für Politikwissenschaft №31, 2002. S. 285.

Werner T. Bauer. Rechtsextreme und rechtspopulistische Parteien in Europa. Wien, 2014. S. 5.

Werz N. Populismus. Populisten in Übersee und Europa, Opladen 2003. S. 15-43.

Zinnel A. Moderner Rechtspopulismus in Frankreich, Frankfurt am Main, 1996. S. 15-18.

\section{Right-wing Populism as a political phenomenon}

Author. Vasily Gribovsky, Master of Political Sciences, Junior Research Associate, Institute of Europe, Russian Academy of Sciences. Address: 11-3, Mokhovaya str., Moscow, Russia, 125009. E-mail: vasily.gribovsky.92@mail.ru.

Abstract. Given the strengthened the «political alternative party» in contemporary Europe, research in the field of right-wing populism is getting increasingly relevant. To date, European political science has developed a general concept of this phenomenon, but many theoretical issues remain controversial. This article analyzes right-wing populism as a socio-political phenomenon and answers the question of the criteria of right wing populist party.

Key words: Populism, parties of political alternative, the European Union, the European integration, immigration, social-economic issues.

DOI: http://dx.doi.org/10.15211/vestnikieran120196164 